Etnográfica

Revista do Centro em Rede de Investigação em

Antropologia

vol. $16(3) \mid 2012$

Vol. $16(3)$

\title{
“Tu não és daqui... estás só aqui durante um tempo!": explorando os lados sombra de uma experiência de trabalho de campo
}

"You are not from here... You are only here for a while!": exploring the shadow sides of a fieldwork experience

\section{Humberto Martins}

\section{(2) OpenEdition}

\section{Journals}

\section{Edição electrónica}

URL: https://journals.openedition.org/etnografica/2112

DOI: 10.4000/etnografica.2112

ISSN: 2182-2891

\section{Editora}

Centro em Rede de Investigação em Antropologia

\section{Edição impressa}

Data de publição: 1 outubro 2012

Paginação: 525-546

ISSN: 0873-6561

\section{Refêrencia eletrónica}

Humberto Martins, «"Tu não és daqui... estás só aqui durante um tempo!": explorando os lados sombra de uma experiência de trabalho de campo», Etnográfica [Online], vol. 16 (3) | 2012, posto online no dia 08 outubro 2012, consultado o 11 fevereiro 2022. URL: http://journals.openedition.org/ etnografica/2112; DOI: https://doi.org/10.4000/etnografica.2112

\section{(c) (†) \&}

Etnográfica is licensed under a Creative Commons Attribution-NonCommercial 4.0 International License. 


\section{“Tu não és daqui... estás só aqui durante um tempo!": explorando os lados sombra de uma experiência de trabalho de campo}

\section{Humberto Martins}

Neste artigo dou conta de três episódios relacionados com o meu trabalho de campo na fronteira luso-galega (2000-2004). Refletirei globalmente sobre a etnografia como experiência individual e social, por um lado, e sobre os limites éticos e metodológicos ultrapassados ou impostos durante aquele período, por outro. Os episódios, fruto de relações e interações sociais específicas, mantiveram-me em diferentes fronteiras experienciais; em última instância, causaram estranheza e funcionaram como espelhos refletores de uma presença circunstancial que interrompeu a suposta "normalidade" de um terreno de estudo, numa antropologia que, aparentemente, foi feita "em casa". O texto revela-se, assim, como um contributo relevante para a prática do trabalho de campo, não só e em particular considerando o estudo do mundo rural português contemporâneo mas, também, porque nos mostra as múltiplas interações em que participou o antropólogo quando no terreno.

PALAVRAS-CHAVE: etnografia, trabalho de campo, reflexividade, interações sociais, antropologia visual.

"You are not from here... You are only here for a while!": exploring the shadow sides of a fieldwork experience - In this article I refer to three episodes that occurred during my fieldwork in the Portuguese-Galician border (2000-2004). On the one hand I reflect globally on ethnography as a social and an individual experience, and, on the other hand, I approach methodological and ethical limits that were imposed or exceeded during that period. These episodes, which were an outcome of specific social interactions and relations, kept me in distinct experiential frontiers. Eventually they caused strangeness and functioned as mirrors, reflecting a circumstantial presence that interrupted the "normality" of that fieldwork setting in an anthropology that, apparently, took place "at home". The text turns to be a significant contribution to fieldwork practicing, not only and in particular considering the study of the contemporary Portuguese rural world but also because it reveals the multiple interactions in which the anthropologist engages with when in the field.

KEYWORDS: ethnography, fieldwork, reflexivity, social interactions, visual anthropology.

MARTINS, Humberto (humbmsm@yahoo.com) - Centro em Rede de Investigação em Antropologia, Instituto Universitário de Lisboa - ISCTE-IUL; Cetrad, Universidade de Trás-os-Montes e Alto Douro, Portugal. 
NESTE TEXTO PROPONHO-ME REFLETIR SOBRE A ETNOGRAFIA COMO metodologia e como processo de produção de conhecimento, no quadro de experiências interpessoais ocorridas no percurso de um trabalho de campo na fronteira luso-galega (2000-2004). ${ }^{1}$ Para tal, falarei de relações e interações sociais que mantive com os sujeitos do meu estudo durante esta pesquisa que resultou numa etnografia escrita em inglês na universidade de Manchester. ${ }^{2}$ Em particular, dou conta de três (im)previstos que me marcaram pessoalmente, refletindo sobre essas situações não apenas como experiências pessoais, mas também sobre a forma como resultaram em conhecimento etnográfico. Durante o período em que estive no terreno realizei uma pesquisa que fez uso de meios visuais (vídeo e fotografia), vivendo durante quinze meses seguidos (2000-2002) em Tourém (Montalegre) e na zona de fronteira citada, com períodos mais curtos em 2003 e 2004. Durante aquele tempo, vários episódios marcaram a minha experiência, que, como qualquer outra de longa duração, foi única, intensa e criadora ou redescobridora de novos traços de identidade.

Foram episódios nos quais os limites metodológicos, no sentido do que se poderia pressupor ser a normalidade do processo de investigação (existindo normalidade em trabalhos de investigação desta natureza), foram levados a um extremo tal que me implicaram em necessárias considerações éticas. Considero-os como imprevistos no sentido em que, literalmente, não esperava que tivessem surgido naqueles momentos; ou seja, não os previra antecipadamente. Todavia, por terem acontecido, tiveram um efeito muito importante - o de estimular uma atitude continuada de refletir sobre o modo como ia conhecendo.

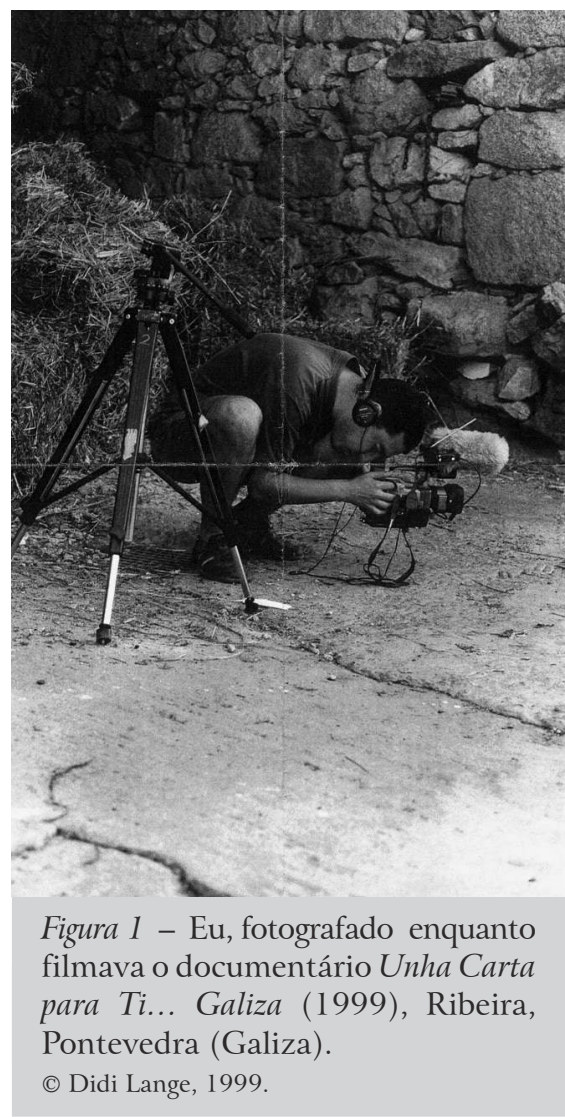

1 Este texto inspira-se na comunicação com o mesmo título apresentada no IV Congresso da APA, no painel "Imprevistos e imponderáveis: condições de produção da etnografia na antropologia contemporânea”. Agradeço os esclarecidos comentários do José Mapril e da Susana de Matos Viegas.

2 Este trabalho foi realizado para uma tese de doutoramento em antropologia social com uso de meios visuais sobre relações de fronteira e memória social (Martins 2005). 
Por outro lado, e como referirei, sinalizaram de forma clara que eu não estava sozinho ali. Tudo o que fazia era visto e analisado por aqueles que queria estudar e, no limite, era a minha própria forma de investigar antropologicamente que estava a ser analisada pelos sujeitos da minha pesquisa. Talvez não formulados de um modo consistente pelos próprios, a verdade é que estes episódios imprevistos foram matéria importante não apenas para mim e para a minha reflexão mas, igualmente, para aqueles que estudava. Através daqueles episódios, a minha pesquisa tornou-se mais visível ou, provavelmente, a minha presença mais óbvia.

Refiro, mais em particular, dois episódios relacionados com etnografia convencional e um relacionado com etnografia visual, que fizeram estranhar-me numa suposta antropologia feita em casa. ${ }^{3}$ Os imprevistos na minha etnografia estão intimamente ligados a processos de estranhamento, auto ou heterossuscitados. Isto é, a imprevisibilidade das situações clarificou as minhas ignorâncias, expondo, neste sentido, a minha exterioridade ou não pertença àquele contexto social particular (apesar de ser parte do meu país). Em concreto, abordarei (i) a avaliação negativa do meu envolvimento opinativo num debate local sobre a passagem do gado na aldeia feita por um nativo residente, (ii) a ameaça que um homem me fez por entrevistar a sua mulher no café e (iii) a minha incapacidade, por constrangimento moral, de filmar a morte da Tia Lucinda, o seu corpo e os ritos associados à cerimónia fúnebre - o que, aliás, fez espoletar um outro imprevisto, o da reação do seu sobrinho, "exigindo-me" que tivesse filmado. Foram situações e interações em que estive envolvido e para as quais em tese e em abstrato poderia dizer que não tinha nem tive solução clara e previamente ensinada para as enfrentar (e resolver); tive de criativamente repensar não só procedimentos, mas, também, atitudes relativas à minha própria investigação e àqueles que procurava conhecer.

$\mathrm{Na}$ verdade, a etnografia realizada implicou-me em sucessivos e distintos processos negociais com diferentes interlocutores, fazendo reconhecer três aspetos principais: (i) um trabalho de campo de raiz etnográfica constitui uma experiência individual e social intensa que ultrapassa a simples esfera profissional ou metodológica; (ii) nem sempre estamos preparados em termos de ferramentas metodológicas e de um esclarecimento ético claro sobre situações e interações sociais específicas que ocorrem durante um trabalho de campo de raiz etnográfica; (iii) uma suposta neutralidade e objetividade do investigador, se é que têm de existir, são hoje, talvez mais do que nunca, constantemente confrontadas com os efeitos da inevitável e desejada copresença dos sujeitos das nossas etnografias; as pessoas não estão só lá para ser conhecidas ou para se deixarem conhecer - são agentes ativos, coprodutores do conhecimento

3 Faço distinguir etnografia visual, como produto e como processo, quando refiro o uso e/ou a produção audiovisual para fins de investigação de raiz antropológica. 
antropológico que influenciam continuadamente os investigadores nas suas tomadas de decisão e nos seus posicionamentos éticos.

No meu caso particular, este terceiro aspeto teve um impacte ainda maior porque, por um lado, realizei uma antropologia ao nível dos indivíduos, que partiu do pressuposto de que todo o conhecimento produzido é mediado de forma circunstancial por elementos biográficos que influenciam as diferentes interações e situações pelas quais vamos passando ao longo da investigação (e não falo apenas dos indivíduos que estudei, senão dos meus próprios percursos autobiográficos) e, por outro, porque realizei uma etnografia visual que incluiu fotografia e filmagens. Nas imagens, os sujeitos dos nossos estudos estão mais expostos e conseguimos acessos mais diretos não só aos seus corpos e rostos, como às suas emoções e afetos.

Poderíamos ainda acrescentar uma outra consideração importante, em particular no âmbito da antropologia visual, que se prende com as avaliações projetivas por parte daqueles que são sujeitos que estudamos sobre a representação que sobre eles será produzida; isto é, a capacidade de decidir sobre o que mostrar e como mostrar num processo de fabricação altamente criativo sustentado por grelhas narrativas e performativas que penetram as suas (nossas) vidas através, nomeadamente, da televisão ou da Internet. Este pressuposto está ancorado no reconhecimento de que as pessoas, na sociedade portuguesa, têm hoje um acesso mais facilitado a mais informação e que, consequentemente, estão hoje mais conhecedoras dos estudos que vão sendo feitos sobre elas. ${ }^{4}$

No subtítulo deste texto designo estes episódios como os lados sombra do trabalho de campo porque se referem às dimensões da nossa presença no terreno que nos ajudam a contar e a perceber melhor o que lá se vai passando, a circunstanciar os diferentes processos de produção de conhecimento e representação que encetamos desde o momento da nossa entrada no terreno até ao seu (impossível) término. A referência à palavra sombra resulta da leitura da obra organizada por McLean e Leibing (2007), na qual os autores se propõem explorar as ténues ou impercetíveis fronteiras entre etnografia e vida pessoal. São, igualmente, sombra porque são muitas vezes negligenciados ou omitidos; ponto no qual imbrica a obsessão de Fabian $(1983,2008)$ na crítica a uma antropologia que se afasta dos próprios encontros e dos momentos dialógicos que vamos tendo ao longo do tempo de trabalho de campo e que são definidores de muito mais do que apenas os contextos comunicativos circunstanciais, nos momentos de trazer o terreno de estudo ao conhecimento público e publicado (normalmente, através de artigos ou livros). Como refere Fabian, nos atos de transcrição para texto existe sempre redução e a tendência para omitir factos e aspetos que são definidores dos momentos de criar conhecimento;

4 Não por acaso várias pessoas na minha primeira abordagem referiram que costumavam andar por ali a fazer perguntas, fotografar e filmar. 
para este autor a etnografia é sempre performativa e não apenas informativa (Fabian 2008). ${ }^{5}$

Neste sentido, penso ser importante ativar como referência a ideia constantemente reiterada de que a antropologia é feita com (e para) aqueles que estudamos. Como nos diz Ingold (2006 [2000]), numa alusão ao que considera ser a marca distintiva da antropologia, não é só o facto de estudarmos pessoas, as suas experiências e contextos, que nos singulariza no mundo das ciências (sociais), mas o de o fazermos com elas; Kuper fala na "[reconciliação], a um mesmo nível, das experiências e conceptualizações do ator e do observador" (1992: 1), na procura crítica de conhecermos o que os sujeitos dos nossos estudos pensam e fazem. ${ }^{6}$ Não creio, igualmente, que a pergunta subjacente - para quem é feita a antropologia? - tenha de ser resolvida em jeito de resposta unívoca e assertiva. Prefiro dizer que a antropologia serve para nos conhecermos, sendo estes “nós", implícitos, tão alargados quanto restritos. Isto é, depende de muitos fatores que extravasam o trabalho mais imediato do/a antropólogo/a que faz uma pesquisa em concreto. Fatores tão diversos como os que se relacionam com mercados editoriais, literacia, domínio de línguas e aplicabilidade direta influenciam os putativos destinatários da antropologia.

Por outro lado, o mundo onde hoje se faz antropologia está diferente (também pelo facto de nele se ter vindo a fazer antropologia). ${ }^{7}$ Apenas para referir dois aspetos da questão, diria que não só os sujeitos da investigação são diferentes, como são outras as possibilidades de comunicar ciência (com as imagens a terem um papel crucial nesta mudança). ${ }^{8}$ Estará aqui um dos pontos-chave para o entendimento das novas condições de produção da etnografia. O mundo muda, eu mudo, nós mudamos, eles mudam (permitam-me a cansativa conjugação verbal) e este reconhecimento é em si suficiente para que

5 Fabian (2008) refere-se à pouca atenção dada pelos investigadores à avaliação crítica do trabalho de transcrição, ou seja, de transposição do registo de um evento oral para um documento literário.

6 Nem sempre tem sido assim; por exemplo, na fase evolucionista-especulativa da antropologia, nas etnografias históricas ou nas etnografias multissituadas (Hannerz 2003), os investigadores não estão sempre nos mesmos locais e fisicamente com as mesmas pessoas, e realizam as suas pesquisas através de suportes como a Internet - algo que ajuda a repensar o próprio trabalho de campo na sua aceção mais original (uma experiência de vida na comunidade tendo acesso aos aspetos diários e quotidianos e dominando aspetos vernaculares). Todavia, mesmo estando distantes no tempo histórico e/ou em termos de proximidade física, é a ideia de aproximação (close-up) ao ponto de vista nativo que marca o projeto intelectual da antropologia.

7 A escolha que fiz por um regresso temático ao mundo rural, insistindo metodologicamente num estudo de longa duração tipo malinowskiano, teve na sua génese a ideia de que o mundo rural português oferece no século XXI objetos de estudo novos e interessantes.

8 Singer (1992) fala de uma "anthropology on [prime-time] television", aludindo à série $\mathrm{O}$ Mundo em Extinção (Disappearing World), produzido pela Granada Television (ITV) em colaboração com o Departamento de Antropologia da Universidade de Manchester, como uma tentativa de fazer chegar ao grande público britânico, em horário nobre, a diversidade cultural no mundo dos anos 70, 80 e 90 . Literalmente, os espectadores podiam conhecer outras geografias e outras culturas enquanto jantavam. 
o trabalho de campo etnográfico mereça ser permanentemente estudado e analisado como processo e não apenas nos seus resultados. ${ }^{9}$ Falamos, portanto, do projeto comparativo de uma ciência que se faz entre o local e o global ou entre os acessos diversificados e individualizados à realidade social e a possibilidade de abrirmos essas janelas de conhecimento à comunidade humana mais vasta (académica e não só). ${ }^{10}$ Como veremos, por um dos episódios retratados, a antropologia visual permite uma maior difusão dos produtos do conhecimento e dos processos de representação na antropologia.

DE REGRESSO... (A CASA?):

UM ESTRANHAMENTO IMPREVISTO MAS NECESSÁRIO

O título deste artigo, “Tu não és daqui... estás só aqui durante um tempo!”, transcreve uma frase escutada e a mim dirigida aquando de um dos muitos debates presenciados e participados na aldeia de Tourém. Recuperei-a para este texto para mostrar como a nossa presença num contexto de investigação, por maior ou menor que seja a afetividade, por maior ou menor que seja a ligação familiar, no duplo sentido de parentesco e/ou de partilha de inscrições culturais e simbólicas com uma comunidade de indivíduos mais vasta, está sempre condicionada a fatores de estranhamento; estes estranhamentos não são só por nós vividos e percebidos, nem que seja através da criação de novas perspetivas ou de novos posicionamentos de observação sobre o que já julgamos conhecer (e importa fazê-lo, em particular quando estamos em terrenos de estudo que julgamos conhecer integralmente), ${ }^{11}$ mas, também, acionados por todos aqueles que não conseguem inscrever-nos em linhas de referência ou familiaridade. Nesta aldeia, pela sua situação geográfica "dentro da Galiza", esse quadro genealógico encontra-se alargado a um território internacional do qual fazem parte as famílias e os indivíduos das aldeias galegas mais próximas.

De Manchester, após uma curta paragem em Lisboa, cheguei a Tourém em Julho de 2000. Estranhei e estranhei-me por não conhecer e reconhecer parte do meu país. Supus que ia fazer antropologia em casa. Num certo sentido, isso ocorreu. Mas os estranhamentos sentidos foram muito mais determinantes.

9 Sobre as novas (im)possibilidades do trabalho de campo antropológico num mundo contemporâneo, ver Marcus (2006) e Marcus e Okely (2007). O debate entre Rapport e Stade (2007), a propósito de uma antropologia do cosmopolitismo e/ou de uma antropologia cosmopolita, situa-nos, igualmente, nas novas condições sociais de produção do conhecimento antropológico.

10 Revejo neste desígnio dois importantes debates na história da antropologia: um primeiro que nos relança a relação interdisciplinar entre a história e a antropologia e um segundo sobre os limites de pertinência e as escalas do conhecimento antropológico (Pina-Cabral e Lydall 2008).

11 Releio, a este propósito, Judith Okely, “[o]trabalho de campo em casa não é só uma questão de memorizar um novo vocabulário, só lentamente percebi que tinha de aprender uma outra língua nas palavras da minha língua materna" (1996: 23). 
Passadas umas semanas fui designado como o "alentejano". A atribuição desta alcunha deveu-se à minha própria inscrição familiar, que partilhei com todos aqueles com quem ia interagindo. Toda a minha família é do Alentejo. Este facto, esta nomeada, remeteu-me para um Sul, que, em bom rigor, facilitou o reconhecimento das minhas ignorâncias relativas àquele Norte de Portugal. Ou seja, não só me abriu linhas explicativas mais demoradas por parte daqueles que queria escutar e conhecer, como, em relação ao meu próprio processo de conhecimento, me deixou mais alerta e atento. E não foi só uma diferença entre Sul e Norte, foi também entre um mundo rural e um mundo urbano, entre o universo universitário e o universo agropastoril.

Disponibilizei-me a conhecer, de uma certa forma, ao aceitar ser conhecido e reconhecido como alguém que, embora sendo português, não pertencia àquele Norte rural. Ou seja, não era estrangeiro mas também não era um deles, em particular no início da minha experiência etnográfica na aldeia, nos relacionamentos e interações com os lavradores do sexo masculino. Apesar de ter identificado experiências de relacionamento muito diferentes, porque cada pessoa tinha histórias de socialização específicas, houve inicialmente uma desconfiança muito grande relativamente ao que me propunha fazer por parte de alguns destes homens, alguns sem nunca terem vivido fora da aldeia. Não obstante ter tido o cuidado de tudo explicar, pedindo sempre autorizações para as minhas inquirições e observações, a verdade é que, neste primeiro período de campo, algumas pessoas negaram abordagens ou proferiram alguns insultos pessoais. ${ }^{12} \mathrm{Na}$ verdade, os meus dois principais gatekeepers - José e Maria tinham uma experiência de vida fora da aldeia, o que fez com me situasse, seguramente, numa certa distância inicial face ao grupo dos lavradores. José foi estivador em Lisboa e, embora nunca tenha deixado de vir regularmente à aldeia, a verdade é que não tinha, à altura da minha presença, um estatuto social local de lavrador. "Lavrador" corresponde a uma autocategorização local (à escala regional do Barroso) que designa um modo de vida assente no cultivo da terra ou na criação de gado (a principal atividade económica na aldeia) e marca um estatuto social enraizado numa estética de base camponesa e numa relação de longa duração com a terra (no duplo sentido, de lugar de nascimento e de espaço de trabalho e sustento). Cultivava a terra mas não tinha gado, a marca distintiva principal naquela aldeia do ser "lavrador". Também Maria, que visitava a aldeia três vezes por ano, era uma "lisboeta"; ou seja, vivia na Costa da Caparica há muito tempo e estava mais fora do que dentro da vida social local. A distância relativamente aos lavradores foi sendo progressivamente ultrapassada, em especial no fim do verão quando os "emigrantes"

12 Talvez o mais ofensivo tenha sido o de um ex-guarda fiscal que me apelidou de "ladrão", dizendo que eu queria roubar os "velhos". A pessoa que proferiu o insulto não vivia regularmente na aldeia. 
vagaram a aldeia. Nessa altura perceberam que eu iria mesmo continuar por ali e fiquei, de facto, por mais treze meses.

No início dos anos 1980, João de Pina-Cabral (1983) refletia sobre as (im)possibilidades de uma antropologia em casa, salientando, em particular, as dificuldades e virtudes de uma etnografia em contexto rural. Apesar de se referir a um país e a um mundo que já não são assim, não deixa de ser significativo que a minha experiência etnográfica no mundo rural português em 2000-2004 tenha ecoado muitas das coisas sobre as quais o autor reflete. Como refere posteriormente, no prefácio à sua etnografia no Alto Minho, o antropólogo deve identificar e explicitar todas as circunstâncias que afetam o seu trabalho de investigação (Pina-Cabral 1986). Neste particular, o facto de supostamente estar a fazer "antropologia em casa" não era para mim, nem o foi para Pina-Cabral ou José Cutileiro (1971, 1977), uma coisa a assumir sem considerandos. Fazia um trabalho que era sobre parte do meu país que, provavelmente, me era mais estranha do que aquela Inglaterra urbana, globalizada, de onde tinha acabado de chegar. ${ }^{13}$

\section{OS IMPREVISTOS ETNOGRÁFICOS NO TEXTO ESCRITO E NA IMAGEM}

$\mathrm{Na}$ etnografia que resultou desta investigação e constituiu o corpo da minha tese de doutoramento, a experiência de trabalho de campo foi "trazida" para o texto principal desde o seu primeiro momento. A tese começa com o relato da minha primeira viagem para Montalegre e ao longo do texto, num estilo novelístico e dialógico, vou mantendo as conversas em aberto com os indivíduos que encontro, ao mesmo tempo que apresento os meus próprios dilemas ligados à investigação (Martins 2005). De facto, os episódios a que me irei referir agora estão já identificados em texto científico principal, se assim o posso designar. Entendi que a minha presença no terreno e o modo como ela suscitou reações, relações e interações devia ser, de forma reflexiva, tornada explícita ao longo do processo textual de criação de conhecimento. Tal não significou, num pós-modernismo extremo, que os objetos e os sujeitos do meu estudo fossem tornados secundários à luz dos jogos de espelhos a que me ia submetendo e que, por fim, seria o antropólogo a tornar-se motivo de interesse. Pelo contrário, tratou-se de dar relevo às dimensões de subjetividade na criação do conhecimento e representação na antropologia e reconhecê-lo na sua imensa

13 Mais tarde, em 1998, Pina-Cabral, num artigo muito crítico de certos posicionamentos disciplinares no seio das ciências sociais que parecem querer anunciar o "fim da antropologia" (por aparente falta de objeto de estudo num mundo contemporâneo sem exóticos), põe em causa esta ideia de antropologia em casa. No entanto, a posição do autor não advém do facto de não achar importante refletir sobre a realização de pesquisa em contextos de proximidade sociocultural, mas mais como forma de traçar a história da disciplina num tempo longo que não a exclui dos contextos urbanos e modernos. 
multiplicidade como o lado crucial da própria ciência antropológica: os encontros, as trocas de olhares, as impressões, são matéria imprescindível da abordagem antropológica de base etnográfica. Até porque são vários os espetros que é possível observar numa investigação; o espetro metodológico é, muitas vezes, abordado de forma mais ou menos explícita, diluindo o "eu" (pessoal, subjetivo) em artifícios textuais ou oral-discursivos que parecem negar que aquilo que vemos ou escutamos é intermediado pela nossa presença, uma presença específica e definidora, por relação, do conhecimento obtido.

No âmbito da antropologia visual e, em particular, do filme antropológico, tem existido uma crescente preocupação teórica e metodológica por dar a conhecer e partilhar com as audiências os processos de construção das representações - e nem é preciso recuar aos tempos primordiais de Robert Flaherty ou, mais recentemente, à antropologia partilhada de Jean Rouch ou colaborativa do casal MacDougall. O virar da câmara para o realizador, o ouvir-se a voz de quem pergunta, o sentir da presença de quem filma é hoje, numa certa cinematografia do real, procedimento metodológico fundamental - disponibilizando a quem vê e conhece, intermediamente, a posição física e social de quem foi intermediário dessa relação de conhecimento (não só no momento do contacto direto da recolha de imagens mas, igualmente, da edição posterior). Falamos de reflexividade e de subjetividade nos processos de produção de conhecimento através das imagens (Pink 2001, 2003).

A este propósito importa também referir uma questão crucial que se coloca de forma cada vez mais premente no seio da pesquisa com meios visuais e que tem suscitado, no Reino Unido e em particular no âmbito do ESRC (Economic and Social Research Council), uma produção muito abundante de texto (AAVV 2008). Falo sobre os diferentes níveis de consentimento para efeitos de produção e divulgação de conhecimento sobre outros. Os autores, reconhecendo proximidades e zonas de confluência entre métodos visuais e métodos convencionais, nomeadamente ao nível das relações interpessoais que se estabelecem, enfatizam o problema da utilização da informação e a sua posterior divulgação e circulação não consentida ou não voluntariamente consentida em termos de implicações totais. A questão ganha importância se considerarmos que vivemos num mundo global em que tecnologicamente é possível manipular digitalmente a informação e fazê-la circular por todo o lado muito rapidamente (AAVV 2008).

Por outras palavras, quando mostramos (ou falamos de) alguém damos conta de todas as implicações da utilização da nossa informação? Daí que seja importante falar em diferentes níveis de consentimento - correndo o risco de, por respeito de anonimato ou consentimento, a representação integral não ser atingida e, logo, de a representação se tornar inapropriada. A questão está em que nos métodos audiovisuais, que culminam em produtos como fotografias e vídeos, são as expressões físicas, os rostos, os olhos, que conferem integralidade 
à representação - as epistemologias tácteis ou formas hápticas de conhecimento devem muito a este acesso às sensações e aos corpos em movimento (Grimshaw 2005). Eliminar o acesso aos rostos, por exemplo, significa a aniquilação das virtudes epistemológicas destas abordagens.

Finalmente, a opção de tornar central o processo de produção de conhecimento, equalizando-o a um nível da própria representação e conhecimento produzidos, foi também suscitada pelo facto de me ter proposto fazer uma antropologia ao nível dos indivíduos (Rapport 1997; Lahire 2003), que não procurava os traços de semelhança, mas os traços biográficos ou de história particular e individual que individualizavam cada homem e cada mulher num quadro de efetivas proximidades culturais e sociais.

\section{ESTRANHAMENTOS SUSCITADOS:}

\section{O QUE POSSO DIZER E COM QUEM POSSO FALAR?}

O primeiro imprevisto que afloro decorreu do meu envolvimento opinativo sobre um debate que é travado há alguns anos na aldeia, sem que efetivamente tenham ocorrido grandes tomadas de decisão. Ouvi a frase "Tu não és daqui... estás só aqui durante um tempo!” passados cerca de nove meses da minha entrada e presença no terreno de estudo. A afirmação de um reformado, ex-lavrador e ex-emigrante, foi produzida aquando de uma intervenção minha com tomada de posição sobre um conflito que continua a marcar as relações e representações sociais dos indivíduos na aldeia e na comunidade; o conflito tem que ver com a passagem do gado bovino nas ruas calcetadas (principais) do povoado. O conflito, não totalmente esboçado na forma dicotómica pura que aqui apresento por motivos de exposição, pode ser formulado da seguinte maneira: há pessoas que acham que a aldeia deve manter a sua originalidade, ou seja, a sua vida e estética camponesa, o que, curiosamente, se torna objeto de desejo do turismo predominante no Parque Nacional da Peneda-Gerês (onde a aldeia se situa), e há outras pessoas que dizem que o gado e, em geral, todos os animais (galinhas, pintos, cabras, ovelhas e cavalos) deviam apenas passar pelos caminhos à volta do aglomerado urbano ou pelas ruas secundárias, de forma a não sujar as ruas principais nem pôr em causa a segurança das pessoas e dos veículos (toques de chapa, retrovisores partidos, etc.). O conflito de opinião é comparticipado também por pessoas que, não morando na aldeia, ali nasceram ou estão ligadas por laços de parentesco e por pessoas que compraram uma segunda casa na aldeia.

A minha posição e opinião em relação ao assunto em causa foi a de que o gado deveria continuar a circular na aldeia, não devendo existir preocupações estéticas com a bosta deixada no chão que pode incomodar o turista, a urina entretanto vertida pelas vacas e bois que passam, ou, mesmo, outras preocupações ligadas aos odores. Perante a reação que tive na altura, esse homem, 
de forma educada e contextualizada, disse-me: "Humberto, tu dizes que não te importas que as vacas passem, que a bosta fique... porque não vives aqui, estás aqui agora, fazes um trabalho (escreves o livro) e depois partes... mas nós estamos cá sempre, andámos descalços, partimos, voltámos. Os tempos são outros..." As palavras deste homem acionaram um dos muitos argumentos possíveis em torno da questão - e a questão não é de fácil solução; tem que ver com o próprio futuro das aldeias rurais como destinos meramente turísticos ou como lugares de trabalho agrícola que podem muito bem coincidir com visitantes à procura da paisagem, lazer e aventura. E, na verdade, esta aldeia, como outras semelhantes, vive na fronteira de um passado rural-agrícola e de um futuro rural-turístico, entre investimentos sustentados por apoios comunitários (que agora começam a diminuir) numa agropastorícia de pequena dimensão e as oportunidades de um turismo de casas rurais que explora as paisagens naturais marcadas pelos trabalhos agrícolas (Martins 2005). Todavia, trago a afirmação a este escrito pela importância que teve no meu próprio processo de produção de conhecimento sobre aqueles indivíduos, aqueles lugares, aqueles passados, aquelas memórias e relações sociais. Quando estamos a fazer uma investigação, somos elementos neutros? Elementos implicados e aplicados? Pessoas (homens e mulheres), simplesmente em interações "normais" e regulares? Quais os critérios para definir essa normalidade, essa regularidade?

Aquele "tu não és daqui", atirado, num certo sentido, a "matar", obrigou a que me posicionasse num determinado quadro de referências e possibilidades de participação na vida da aldeia. Não foi dito, contudo, no sentido de me excluir, de me fazer o estrangeiro ali; pelo menos, não o senti dessa forma. Penso que, num outro sentido, poderia ser convidativo, como que uma tentativa de implicar-me mais estruturalmente na vida da aldeia. Do género "porque não vens viver para aqui?" Mas, por outro lado, também houve ali alguma agressividade, um colocar em sentido, do género "Humberto, vê, conhece, tenta saber que nós ensinamos (mostramos)... mas limita-te a isso... Tenta não projetar juízos de valor”. Recuei naquela conversa, em particular, para uma posição de escuta. A tentativa de me implicar num dos debates coletivos mais cruciais na aldeia foi por mim travada. Afinal, tenho-o em diário de campo: "ainda preciso de recolher mais informação sobre este assunto", escrevi. Vivi ali, como disse, quinze meses. Saí após o trabalho de campo; regresso quase sempre duas vezes por ano, menos (ou mais) implicado, menos (ou mais) estranho. Entretanto, iniciei uma pesquisa sobre a relação entre os indivíduos humanos e os indivíduos animais num estudo em torno dos conflitos e perceção do ambiente em áreas protegidas e no qual abordo, agora de forma mais focada, o debate referido. ${ }^{14} \mathrm{Na}$ altura não o imaginava. Trouxe o exemplo deste episódio pela forma

14 Projeto em curso sobre "conflitos e perceção do ambiente em áreas protegidas" (Parque Nacional da Peneda-Gerês e Parque Natural do Alvão). 
como me fez perceber o meu estatuto naquele terreno particular. Não tenho resposta óbvia ou uma solução sobre o rumo que deveria ter dado à minha intervenção (verbal-oral). Sempre achei, numa estratégia pensada, que deveria ter uma posição de espera (de não intervenção? De querer saber e escutar o outro? Apenas?).

Como falar, com quem? Quando? Onde? São perguntas importantes que iluminam não apenas reflexões de posfácio, mas experiências de momentos, etapas e processos concretos das pesquisas - nos quais a própria investigação se define e redefine. Portanto, o processo de investigação extravasa o âmbito convencionado das metodologias e técnicas ensinadas e treinadas (poderíamos mesmo falar de atitudes e ética) e deve ser entendido como experiência social total (de envolvimento, de sentidos, de subjetividades, de sujeitos que se conhecem mutuamente e de negociações continuadas) - na fórmula de Paul Rabinow, "observar observadores observando" (2007). As representações e os conhecimentos produzidos derivam destes contextos comunicacionais (culturais) que nos envolvem.

No caso particular deste episódio, sinto que tornou também claro que os traços culturais de uma comunidade não são homogéneos, revelando diversidades ao nível dos seus interlocutores. De certo modo, foi isto que procurei (re)conhecer - ou seja, entradas individualizadas no tecido social e cultural de uma comunidade, no âmbito de uma antropologia ao nível dos indivíduos que fizesse acionar aspetos dialógicos suscitados pela minha intervenção. Havia quem quisesse e advogasse um presente e um futuro para a aldeia, do ponto de vista do turismo, alicerçado numa "limpeza" dos seus traços camponeses menos higiénicos, e havia quem, justamente, pensasse o contrário. E, como disse, as posições não estavam apenas e só alinhadas nesta dicotomia estanque. Afinal, também em relação a aspetos de memória fui capaz de verificar, na recuperação de episódios passados, entradas diversas que resultavam de posições distintas face aos acontecimentos vividos. A aldeia e a comunidade não eram aos meus olhos, como nunca foram, entidades e realidades homogéneas e uniformes (Martins 2005).

O segundo imprevisto (após três semanas na aldeia), mais inicial e talvez mais óbvio e expectável, ocorreu quando fui ameaçado por um homem de trinta e poucos anos. A ameaça foi feita porque dias antes, num dos cafés locais, abordara a sua mulher, de vinte e poucos anos, para fazer umas perguntas. A minha interpelação foi feita num momento em que o café estava cheio de pessoas (incluindo os "emigrantes"). Um dia depois, por volta da meia-noite, numa rua escura, oiço a voz de alguém que me diz: "Tu tem cuidado com quem falas... uma noite dessas ainda algo te acontece”. Reconheci a voz e o vulto logo a seguir. Nunca dali a situação passou. Fiquei incomodado. Tirei muitas notas sobre o ocorrido. A ameaça fez-me pensar se estaria a realizar bem os meus passos da investigação - em particular, se seria adequado 
entrevistar mulheres casadas, jovens, no café, depois de jantar, durante o mês de agosto, quando a aldeia volta a encher com o retorno dos emigrantes. Fui incauto ao tentar aquelas abordagens? Não o fiz apenas com aquela mulher; fi-lo com outras. Procurei respostas e possibilidades - uma delas fez-me precisamente sentir estranho no meu país.

Tinha chegado de Manchester, uma cidade com quase seis milhões de habitantes, com tanta gente, com outras gramáticas sociais e culturais. Seguramente, não seria correto fazer entrevistas a mulheres casadas, jovens, abordando-as no café. Afinal, eu era um homem jovem. Mas as respostas não eram simples. Outras mulheres casadas, outras mulheres entrevistadas, outros homens jovens, e nada se passara; nos escritos alinhavados no diário de campo após o momento de questionamento total da minha presença ali (no limite, senti por momentos que talvez tivesse pisado o risco final de consentimentos e que a minha experiência na aldeia tivesse terminado), passei para um processo de interpretação das pessoas em concreto e da situação/interação em que me tinha envolvido; afinal, eram as pessoas concretas, com nomes, identidades, biografias específicas que teriam de ser percebidas; não era uma coisa de mulheres e de homens no geral, apenas. Também é certo que a relação com aquele homem e aquela mulher (e respetivas famílias) evoluiu para outras formas. A relação tornar-se-ia afável e pude realizar entrevistas com ambos. Diria que, neste caso, estava perante um imprevisto previsível, reconhecendo aspetos particulares marcantes das relações homens-mulheres na aldeia e dos acessos diferenciados (permitidos e interditos) aos espaços públicos e nos quais vemos refletidas questões de vergonha e honra, já amplamente discutidas nos estudos sobre sociedades mediterrânicas e do Sul da Europa. Homens e mulheres têm papéis e liberdades diferentes no âmbito das interações e relações sociais nos espaços públicos e nos espaços privados (Martins 2005).

É também, parece-me, característica marcante de todo o trabalho antropológico a sua inerente imprevisibilidade, que resulta do próprio facto de a observação de proximidade nos envolver continuadamente em situações, interações e processos (inicialmente) imprevistos porque a escolha de estar lá com as pessoas que são os sujeitos das nossas pesquisas nos torna interlocutores e participantes de múltiplas situações e interações sociais também elas inimaginadas. A este respeito podemos falar, tendo por referência a ideia de um emicismo endoetnográfico a propósito de uma ciência social de quotidianos e proximidades vivenciais dos investigadores (espaciais, temporais, estéticas, estilísticas, etc.), dos constantes eticismos endoetnográficos clássicos dos antropólogos, sempre à procura de perceberem os sucessivos estranhamentos, enigmas, incoerências e incompreensões com os quais vão deparando. Como costuma referir Paul Henley a propósito da realização do documentário antropológico (observacional), "um (bom) filme tem cinquenta por cento de sorte e cinquenta por cento do reconhecimento dessa 
sorte", ${ }^{15}$ o que, noutras palavras, mais não é do que a capacidade de ter instrumentos previamente organizados para irmos lendo a realidade social que à nossa frente vai tendo lugar - não esquecendo, também, que a nossa participação interativa com aqueles com os quais vamos estando é ela mesma criadora de novas realidades sociais.

Na realização do filme etnográfico - na esteira observacional rouchiana e do próprio Cinema Direto, i.e., de trabalho individualizado (sem grande produção) e de envolvimento continuado com o contexto da pesquisa e com os sujeitos etnográficos -, a imprevisibilidade e o imponderável fazem parte, no momento da recolha de imagens e sons, da matéria vintage da realidade social que importa representar. ${ }^{16} \mathrm{O}$ ponto de ordem estará na capacidade de ir criando criativamente uma história ali, naquela (e daquela) imensa imponderabilidade que caracteriza as nossas vidas humanas (nada se repete) e ter depois a capacidade de em sala de edição fazer a história fluir em formato fílmico. Esta perspetiva segue o argumento de Behar em relação à sua atração original pelo trabalho de campo antropológico (2003). Behar fala da ideia de partir para um lugar e encontrar uma história que não procura, salientando, todavia, a centralidade do autor (etnógrafo) no "fazer" e contar de histórias (2003). O seu argumento é, sem dúvida, o de tornar claro o papel autoral do etnógrafo na construção de um texto, argumento que Fabian subscreve quando enfatiza que "os textos etnográficos não se encontram, fazem-se" (2008: 40) [itálico do autor]. Na verdade, reconhecer os imprevistos como parte das nossas etnografias tem sobretudo a ver com esta proposta - não perder, não "virar a cara" ao que se passa ao nosso redor, mesmo que, originalmente, não fizesse parte das nossas escolhas. As etnografias com trabalho de campo têm esta grande virtude - tornam-nos atores não previstos de uma história que, não sendo normalmente nossa, circunstancialmente se torna a nossa história normal.

\section{IMPREVISTOS ÉTICOS (OU MORAIS?): FILMANDO A VIDA (E A MORTE)}

Tia Lucinda era uma mulher de setenta e nove anos, ex-emigrante em França, na zona de Lyon, onde trabalhou numa fábrica de chocolate. Com ela passei horas e dias, conversando, reativando memórias que ela necessitava recuperar. Falava um português com muitos traços do galego (na aldeia utilizam-se muito vocábulos e expressões galegas) e muitos palavrões. Era mulher de "boas" memórias, da Guerra Civil de Espanha, da emigração, da passagem de emigrantes (os "carneiros"), dos seus dias com o gado no monte, da vida e das vidas

15 Recupero a sua citação com maior ou menor precisão. Não é dos livros, mas das suas aulas.

16 Ou o clássico exemplo de Jean Rouch, que, ao ter partido o tripé no Níger, ajudou a fundar o cinema observacional. A câmara começou a ter a liberdade de movimento do próprio operador de câmara; no caso concreto de Rouch, do realizador (filmmaker). 


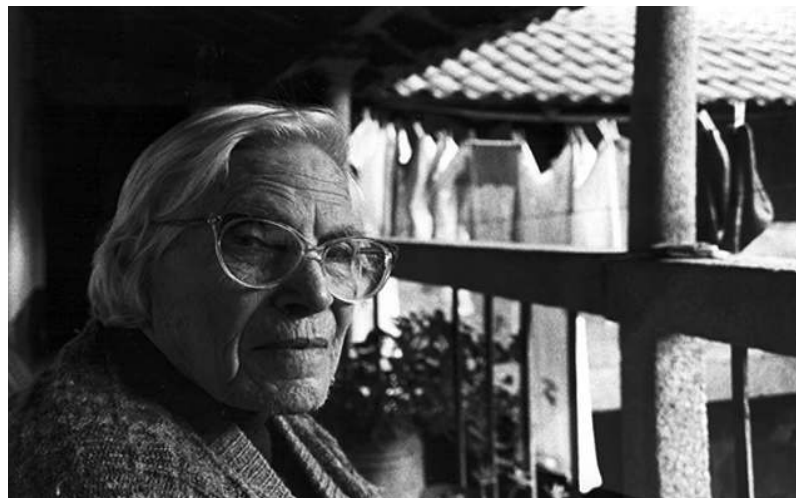

Figura 2 - Tia Lucinda "fazendo o seu tempo" sentada no balcão interior da casa de Lucília. Na altura encontrava-se praticamente cega devido à diabetes. (c) Humberto Martins, 2000. na aldeia. A Tia Lucinda vivia na Casa dos Buracos, um solar de traços nobres (pátio interior com balcão superior - hoje espaço de turismo rural), que eu também partilhava com Lucília e o seu marido, o Sr. Domingos. Lucília tinha por hábito naquela casa receber e cuidar de velhos e velhas da aldeia (não necessariamente com ligações familiares). A troco de uma mensalidade, Lucília cui-

dava de homens e mulheres em fases terminais, por idade ou doença - entre eles, Tia Lucinda, que, à data, se encontrava enferma com diabetes e uma cegueira pronunciada. As nossas conversas eram terapêuticas, diria; comigo ela tinha uma companhia e, sobretudo, as suas necessárias redundâncias narrativas ganhavam uma nova vida porque o interlocutor era novo e queria saber tudo; as histórias no balcão do primeiro andar repetiam-se mas a minha voz ajudava-a, de certa maneira, a ver um pouco melhor - a sua cegueira em estado progressivo deixava-a muito incapacitada nos movimentos. A sua debilidade física acentuou-se. Entre agosto e dezembro de 2000 partilhámos um espaço residencial e muitos diálogos; foi um dos meus melhores interlocutores. Dela recordo também o seu lado crítico em relação ao "tempo de Salazar", pelas dificuldades que, segundo ela, o povo passava e pelas perseguições realizadas pelos guardas-fiscais aos homens e mulheres que andavam no contrabando ("estrapelo") de pequena escala entre a aldeia e aldeias galegas vizinhas.

Desde cedo decidi realizar um documentário que a tivesse como personagem central, numa narrativa que assumisse como fio condutor o modo como os velhos da aldeia, e em particular os mais incapacitados fisicamente, faziam o seu tempo à conversa, ao lume, trocando passados já gastos de tantas recoleções. Por estratégia de investigação decidira começar a filmar apenas em janeiro de 2001, passados seis meses da minha entrada no terreno. Contudo, no dia 30 de novembro de 2000, cerca das dez da noite, Lucília diz-me que deve estar iminente o falecimento de Lucinda. Tinha, curiosamente, acabado de trazer o equipamento de filmar de Lisboa para iniciar alguns exercícios fílmicos. Fui para o quarto nessa noite e a emoção tocou-me; confesso que as lágrimas correram e não mais me preocupava a possibilidade de ficar sem interlocutor apenas por questões de pesquisa. A opção tomada de separar as 
duas abordagens, a visual e a convencional, assim o ditou. ${ }^{17}$ Todavia, sentia que a qualquer momento e, sobretudo, com o inverno (período em que na aldeia mais velhos morrem), Tia Lucinda poderia falecer e o meu projeto não se concretizar. O eventual desaparecimento da Tia Lucinda era uma coisa emocional e afetiva. Todavia, devo igualmente confessar que a vontade de recolher as imagens alimentava um dilema que crescia com o sofrimento de Lucinda. Via-a deitada, moribunda com uma respiração que prenunciava a sua morte. Via-a na antecâmara da sua partida, podia filmá-la e filmar a morte na aldeia, mostrar como se morre (e todos os procedimentos e implicações inerentes) velório, funeral, encontros de vizinhos e familiares.

Mas não fui capaz, fiquei-me pela incapacidade de "trair uma relação" autorizada a um determinado nível. Tia Lucinda morreu na manhã do dia seguinte, 1 de dezembro de 2000. Não consegui, de facto, captar imagens e trazer depois a público os seus momentos de dor. Falhei? Coloquei o lado emocional e afetivo à frente do lado profissional; eu estava ali para fazer um estudo antropológico sobre indivíduos concretos, tendo por objetivo aproximações, o mais possível, completas da realidade. Aliás, um dos sobrinhos de Tia Lucinda disse-me num tom veemente, durante o velório também realizado naquela casa: "Mas porque não filmaste? Seria interessante lá em Inglaterra verem isto! Eles lá não sabem como se morre e como as coisas são no Barroso..." Uns meses antes tinha visto um documentário de Victor Kossakovsky (1989); no filme Losev, durante cerca de cinco minutos, podemos seguir uma sequência na qual um caixão vai sendo coberto de terra; antes podemos ver o defunto sendo velado - o seu rosto é repetidamente mostrado.

A questão dos níveis de autorização liga-se nas abordagens visuais à da própria integridade da representação da realidade. O problema de se perder a realidade como é, tendo de a negociar em primeira mão, tendo de a sugerir, de certo modo, não deixa de ser um entrave importante às questões da normalidade que se procura atingir. Para além das questões emocionais-afetivas que me impediram, efetivamente, de dar seguimento ao meu plano de trabalho (reforço que

17 Advogo que a antropologia convencional e a antropologia visual não devem ser feitas em simultâneo, o que não significa que não sejam complementares ou utilizáveis (e esta é uma das possibilidades mais interessantes dos cruzamentos entre abordagens convencionais e abordagens visuais/sonoras) para mostrar a complexidade e a multiplicidade de perspetivas que cada terreno de estudo, que cada indivíduo, tem inerente e como os terrenos de estudo e os objetos, conforme a diferença de abordagem, podem revelar contradições e incoerências (Martins 2005). A disponibilidade visual e sonora dos objetos antropológicos implica-nos em processos distintos dos utilizados nas etnografias convencionais. Realizamos outras escolhas e combinações sensoriais e, de certa forma, amplificamos o nosso intrometimento na realidade social que estudamos. As câmaras de filmar e as máquinas fotográficas (apesar do tamanho reduzido de algumas) são acrescidos atores sociais que redefinem, uma vez mais, as nossas relações no terreno, por maior familiaridade com esses equipamentos que exista hoje em quase todo o mundo. Por outro lado, há aspetos éticos da investigação visual que não coincidem ou, mesmo, colidem com os da investigação convencional e vice-versa. 
não fui capaz de ligar a câmara de filmar, nem tão-pouco a de fotografar). ${ }^{18}$ Neste episódio dois imprevistos imediatos ocorreram, o da minha incapacidade de filmar e o da resposta imaginativa do sobrinho de Tia Lucinda, que reivindicou a filmagem como ato de representação cultural. Deu-me uma autorização que eu próprio recusei. No entanto, a imprevisibilidade maior residiria nas respostas (afetivas e emocionais) daqueles que a poderiam ter visto em filme póstumo. Enquanto personagem de um documentário Lucinda não representava uma outra pessoa (como nos filmes de ficção). Ela morreria definitivamente.

A morte na aldeia, sobretudo porque lá viviam muitos velhos, fez parte dos meus quotidianos, inclusive para além da minha presença física na aldeia. Num tempo que corria aparentemente mais devagar, como se não passasse (numa certa estética de uma vida e de uma aldeia inalterada), a morte de alguém fazia destruir (ess)a ilusão, ativando o pêndulo da sua marcha (Martins 2005). O meu filme, Fazendo (o) Tempo (2003), tem como personagem central Zé da Paneira. Filmei, autorizado pelo próprio, imagens para um documentário sobre a sua vida na aldeia como lavrador e durante a montagem/edição (já em Manchester) soube da sua morte. ${ }^{19}$ Num telefonema recebido disseram-me que Zé tinha morrido com um ataque cardíaco num lameiro (de forma inesperada). Neste caso, decidi deixá-lo em filme, perpetuando a sua vida - em filme, num certo sentido, podemos congelar realidades. Não foi fácil, uma vez mais, a tomada de decisão. Recebi a notícia quando o filme já estava praticamente montado na sua versão final. Poderia ter voltado atrás. Não o fiz. Desta vez, provavelmente por estar em Manchester, não cedi à emoção de ver mais alguém morrer. Ainda pensei em abandonar a representação daquele homem e das interações nas quais participava. Tinha outro material e poderia ter feito outras escolhas. Naquele caso, pareceu-me que mostrá-lo seria dar-lhe vida, apesar de ter mostrado o filme na aldeia cerca de seis meses após a sua morte.

Mostrei o filme, pela primeira vez, numa sessão realizada na sede da Junta de Freguesia de Tourém. A sala esteve cheia; pedira ao Paulo, presidente da Junta, que organizasse a sessão e convidasse todos os habitantes (cerca de 150 pessoas costumam viver permanentemente na aldeia), entre os quais a Maria da Paneira, irmã de Zé, que também tem papel central no documentário, mas não foi capaz de ver o filme. Ainda hoje (estive recentemente na aldeia em trabalho de campo e almocei em sua casa) não se sente capaz. Os olhos ainda se humedecem, as lágrimas correm sempre que se fala no irmão. Em 2003, quando mostrei o filme pela primeira vez, todos os que estavam naquela sala ficaram emocionados; ouvi (não procurei ver) gritos de

18 Recordo que são paradigmas diferentes; uma câmara de filmar não é igual a uma câmara de fotografar no que diz respeito a criar representações em antropologia e nas ciências sociais.

19 Todas as imagens captadas em fotografia e filme foram autorizadas num primeiro momento de chegada à aldeia e, depois, em cada ação concreta de registo. 
comoção. Afinal, a morte de Zé da Paneira tinha ocorrido apenas seis meses antes. A reação teria sido outra se o filme tivesse sido mostrado apenas anos depois? Não sei. Sei que o livro de geografia humana que Paula Lema (1978) escreveu sobre Tourém, conhecido na aldeia como o "livro verde", tem um conjunto de fotografias nos anexos finais que mostram homens e mulheres que ainda são hoje reconhecidos e que fazem chorar familiares e amigos. Lema estivera em Tourém quando muitos dos velhos de hoje eram jovens. As lágrimas que se soltaram quando vi as fotografias do livro junto com aqueles homens e mulheres revelavam falta ou ausência não só dos que morreram mas da sua própria juventude.

As imagens têm esta virtude, não escondem as pessoas, o que não quer dizer que não escondam atitudes e características pessoais. Também por isso, senti a necessidade de não criar anonimato (com nomes fictícios) em relação a todos os interlocutores que aparecem em texto escrito e em imagem filmada e fotografada. Se o fizesse em relação ao texto estaria a desequilibrar as relações pessoais e de conhecimento que, entretanto, fui estabelecendo. Zé da Paneira ficou em imagem como outros ficam em texto, com nome, voz ou rosto. No caso do Zé o acesso é mais imediato - como experiência sensorial mais completa (ouve-se a sua voz, o seu respirar e o tossir). Outra pessoa que aparece no filme, a Tia Margarida, também já faleceu. Conheci o seu filho este ano, no almoço que referi. Já ouvira falar do filme.

Não obtive autorização para exibições póstumas. Negociei em vida e com vida com o Zé, com Margarida, com Maria e o seu marido Manuel. Escolhi-os pela sua "disponibilidade visual", por uma certa fotogenia antropológica que os tornava mais interessantes no âmbito de uma etnografia visual. O filme mostra uma outra aldeia, ligada ao passado, aos que são velhos, a práticas que perduram (em texto escrito falo da mudança que coexiste com o que parece imutável), um certo ritmo de tempo lento, como se nada tivesse sido alterado desde há muitos anos. ${ }^{20} \mathrm{O}$ filme fica como registo, perpetua-os numa narrativa específica (não tradutora de toda a realidade, é certo) e, contudo, a mudança acontece. Zé da Paneira diz-me, também no filme (em vida, de facto), "Humberto, e quando você vier cá daqui a uns anos vai estar tudo por trabalhar... tudo de monte [referindo-se aos seus lameiros e terras de cultivo na zona de Tourém]; mesmo os porcos já não os poderemos criar!" Apesar da sua perpetuação através do filme e da possibilidade de o manter vivo (ou, como com Maria, de o relembrar falecido), a verdade é que Zé não pode, de facto, comprová-lo enquanto preditor de uma realidade que afinal não pode conhecer (im)previsivelmente. A história do futuro, todavia, fica contada por ele (e vemo-la contada por ele).

20 Apreciação efetivamente produzida por um grupo de turistas ingleses que visitaram a aldeia no verão de 2001 . 
Esta é uma outra virtude do documentário e das imagens na antropologia que, todavia, faz salientar o meu dilema relacionado com a incapacidade de filmar o cadáver da Tia Lucinda ou enquanto morria. E se tivesse filmado a Tia Lucinda? E se a tivesse mostrado depois em filme? Que reações teria? Como eu reagiria? É nesta imprevisibilidade moral - que também é ética, porque, de facto, nunca pedi autorização à Tia Lucinda para filmar a sua morte -, não só minha mas também daqueles que a ela estavam ligados afetivamente, que faço situar este episódio em particular.

\section{APONTAMENTOS FINAIS}

Pina-Cabral, numa sessão de debate que animou a $11 .{ }^{a}$ Conferência da EASA, realizada em Maynooth, na Irlanda, em agosto de 2010, discutindo o ensino da disciplina hoje na Europa, fazia notar (não serão exatamente estas as palavras mas mantém-se a ideia) que a antropologia não podia ficar refém de considerandos éticos que não mais faziam do que, muitas das vezes, impedir o acesso ao conhecimento. ${ }^{21} \mathrm{~A}$ abordagem fazia referência a novos contextos de investigação caracterizados pela multidisciplinaridade. Nas suas palavras reconhecia a necessidade de avançar, ir lá, conhecer, fazer trabalho de campo, produzir etnografias, desconstruir e dissecar os fenómenos sociais e não ter medo de produzir representação sobre a realidade social. O desafio (ou desabafo) energizante corresponde, também, ao da afirmação da antropologia (social) no mundo contemporâneo, no qual enfrenta condições sociais novas (e adversas) entre as quais encontramos as "desconsiderações" feitas pelas outras ciências sociais (Pina-Cabral 1998) e as suas próprias (Strathern 2006).

Estas novas condições sociais não são, nem devem ser, inibidoras do projeto intelectual da antropologia. Revelam, antes, novos contextos de investigação, novos indivíduos, novas interações possíveis, novos factos e fenómenos sociais e, necessariamente, novos imprevistos e novas mutualidades, resultantes, também, do facto de o conhecimento antropológico ser devolvido aos indivíduos estudados e ir permeando as estruturas e relações sociais. A "morte anunciada" (por alguns) da antropologia deve servir também de estímulo à não submissão do/a antropólogo/a, no âmbito cada vez mais comum dos encontros de diversas epistemologias de saber (com códigos de ética específicos associados). Alguns dos novos imprevistos previsíveis nas etnografias resultarão, seguramente, destes contactos interculturais e interdisciplinares. Creio que a validade e o limite de pertinência das propostas antropológicas está, avaliando a minha própria experiência, no facto de podermos dialogar face a face ou através de proximidades com aqueles que estudamos - inclusive outros

21 No EASA journal debate "How do we train future anthropologists - new horizons, more of the same?". 
cientistas. ${ }^{22}$ Senti nos exemplos que trouxe a debate neste artigo que fiz o que tinha de fazer. Seguramente, negligenciei trâmites básicos de uma "boa prática" de trabalho de campo (isto é, não só eticamente informada como metodologicamente refletida). Mas tomei decisões com vista a respeitar dois pressupostos que aqui defendi - o de obter sempre as devidas autorizações, em especial quando se tratou de trabalhar com imagem, e o de não sobrepor a minha voz à dos indivíduos que procurava conhecer.

Por outro lado, trouxe desde o primeiro momento os sujeitos da minha pesquisa para o "palco textual e visual" da mesma. A obsessão com a presença do outro no texto é uma constante da obra de Fabian (1983, 2007 e 2008). Assume Fabian que, deste modo, conseguimos superar uma dificuldade epistemológica crítica em todo o projeto antropológico e que se prende com o facto de pretendermos produzir conhecimento com o outro mas, em texto, ele nos chegar ausente, efetivamente. Tentei fazê-lo; falar de imprevistos e torná-los explícitos em texto principal não só revelou os meus estranhamentos mas, sobretudo, fez descobrir encontros - revelou mais o "outro". Julgo que importa dialogar em texto com quem nos vamos relacionando em processo mútuo de criação de conhecimento - a representação deve depois assegurar que os encontros permanecem, não numa espécie de perenidade impossível (afinal são encontros circunstanciais) mas como base e processo de fundamentação de um certo conhecimento criado. Em texto, aparentemente, as estratégias para o fazer são simultaneamente mais fáceis e mais difíceis de concretizar. Em imagem, as pessoas estão lá; por maior trabalho de autoria que possa existir, mesmo no sentido da ficção total ou de recriação cultural, chegam-nos como indivíduos, subjetivamente imensos, que não se esgotam naquelas imagens (e daí os necessários cuidados a ter em representar bem). Sobretudo, chegam-nos como indivíduos concretos.

Maria da Paneira, num dos últimos momentos de fala do meu filme, di-lo de forma apurada e enquanto aquece na lareira um pote com água: "Não diga a ninguém que está a filmar em Tourém... quer-nos fazer mais pobres do que já somos". Ela reconhece a importância de um plano, de uma sequência numa cozinha antiga, escura do fumo de anos a curar o fumeiro, da sua representação em imagem criada simultaneamente por mim e por ela e da representação que muitos outros espectadores criarão sobre aquele lugar, ela, eu; nunca ela havia mencionado antes, em inúmeras ocasiões que ali estivera sem a câmara de filmar, o (suposto) feio. É Margarida que fecha o filme e o argumento quando diz: "Sempre é melhor ver isto do que outras coisas que passam na televisão... pelo menos são coisas nossas!” É este o sentido que procuro dar às minhas etnografias textuais e visuais - que sejam não só apenas coisas minhas (e de

22 No estudo sobre as áreas protegidas, por exemplo, os cientistas (biólogos, engenheiros florestais, etc.) são atores socais centrais. 
uma academia [inglesa]), mas, também, de todos aqueles que represento antropologicamente em texto escrito e em imagem e que, neste sentido, a representação dos próprios imprevistos (da vida) seja negociada com eles.

\section{BIBLIOGRAFIA}

AAVV, 2008, Visual Ethics: Ethical Issues in Visual Research, ESRC National Centre for Research Methods Review Paper, Working Paper Series 1 1/08, 43 pp.

BEHAR, Ruth, 2003, "Ethnography and the book that was lost", Ethnography, 4 (1): 15-39. CUTILEIRO, José, 1971, A Portuguese Rural Society. Oxford, Oxford University Press.

CUTILEIRO, José, 1977, Ricos e Pobres no Alentejo. Lisboa, Sá da Costa Editora.

FABIAN, Johannes, 1983, Time and the Other: How Anthropology Makes its Object. Nova Iorque, Columbia University Press.

FABIAN, Johannes, 2007, Memory against Culture: Arguments and Reminders. Durham e Londres, Duke University Press.

FABIAN, Johannes, 2008, Ethnography as Commentary: Writing from the Virtual Archive. Durham e Londres, Duke University Press.

GRIMSHAW, Anna, 2005, "Eyeing the field: new horizons for visual anthropology", em A. Grimshaw e A. Ravetz (orgs.), Visualizing Anthropology. Bristol e Portland, Intellect, 17-30.

HANNERZ, Ulf, 2003, "Being there... and there... and there!: reflections on multi-site ethnography”, Ethnography, 4 (2): 201-216.

INGOLD, Tim, 2006 [2000], "Foreword”, em Alan Barnard, Social Anthropology: Investigating Human Social Life. Abergele, Studymates, ix-xii.

KUPER, Adam, 1992, "Introduction", em Adam Kuper (org.), Conceptualizing Society. Londres, Routledge, 1-14.

LAHIRE, Bernard, 2003, "From the habitus to an individual heritage of dispositions: towards a sociology at the level of the individual", Poetics, 31: 329-355.

LEMA, Paula Bordalo, 1978, Tourém: Uma Aldeia do Barroso. Lisboa, Centro de Estudos Geográficos da Universidade de Lisboa, coleção Chorographia.

MARCUS, George, 2006, "Where have all the tales of fieldwork gone?", Ethnos, 71 (1): 113-122.

MARCUS, George, e Judith OKELY, 2007, "How short can fieldwork be?" (Debate Section), Social Anthropology, 15 (3): 353-367.

MARTINS, Humberto, 2005, Will the Rocks Crumble One Day? Past and Present in the Portuguese Galician Frontier, Border Relations and Memories. Manchester, University of Manchester, tese de doutoramento.

McLEAN, Athena, e Annette LEIBING (orgs.), 2007, The Shadow Side of Fieldwork: Exploring the Blurred Borders between Ethnography and Life. Malden, Oxford e Vitoria, Blackwell.

OKELY, Judith, 1996, Own or Other Culture. Londres, Routledge. 
PINA-CABRAL, J., 1983, "Notas críticas sobre a observação participante no contexto da etnografia portuguesa”, Análise Social, XIX (76): 327-339.

PINA-CABral, J., 1986, Sons of Adam, Daughters of Eve: The Peasant Worldview of the Alto Minho. Oxford, Clarendon Press.

PINA-CABRAL, J., 1998, “A antropologia e a questão disciplinar”, Análise Social, XXXIII (149): $1081-1092$.

PINA-CABRAL, J., e J. LYDALL, 2008, "Larger truths and deeper understandings" (Debate Section), Social Anthropology, 16 (3): 346-355.

PINK, Sarah, 2001, "More visualising, more methodologies: on video, reflexivity and qualitative research", Sociological Review, 49 (4): 586-599.

PINK, Sarah, 2003, "Intersciplinary agendas in visual research: re-situating visual anthropology”, Visual Studies, 18 (2): 179-192.

RABINOW, Paul, 2007, "Anthropological observation and self-formation", em J. Biehl et al. (orgs.), Subjectivity: Ethnographic Investigations. Berkeley, University of California Press, 98-118.

RAPPORT, Nigel, 1997, Transcendent Individual: Towards a Literary and Liberal Anthropology, Londres e Nova Iorque, Routledge.

RAPPORT, Nigel, e Ronald STADE, 2007, “A cosmopolitan turn - or return?” (Debate Section), Social Anthropology, 15 (2): 223-235.

SINGER, André, 1992, "Anthropology in broadcasting", em Peter Ian Crawford e David Turton (orgs.), Film as Ethnography. Manchester, Manchester University Press, 264-273. STRATHERN, Marilyn, 2006, "A community of critics? Thoughts on new knowledge", Journal of the Royal Anthropological Institute, 12 (1): 191-209.

\section{FILMOGRAFIA}

MARTINS, Humberto, 2003, Fazendo (o) Tempo, 64 min., Granada Centre for Visual Anthropology.

KOSSAKOVSKY, Viktor, 1989, Losev, 60 min., Leningrad Documentary Film Studios. 